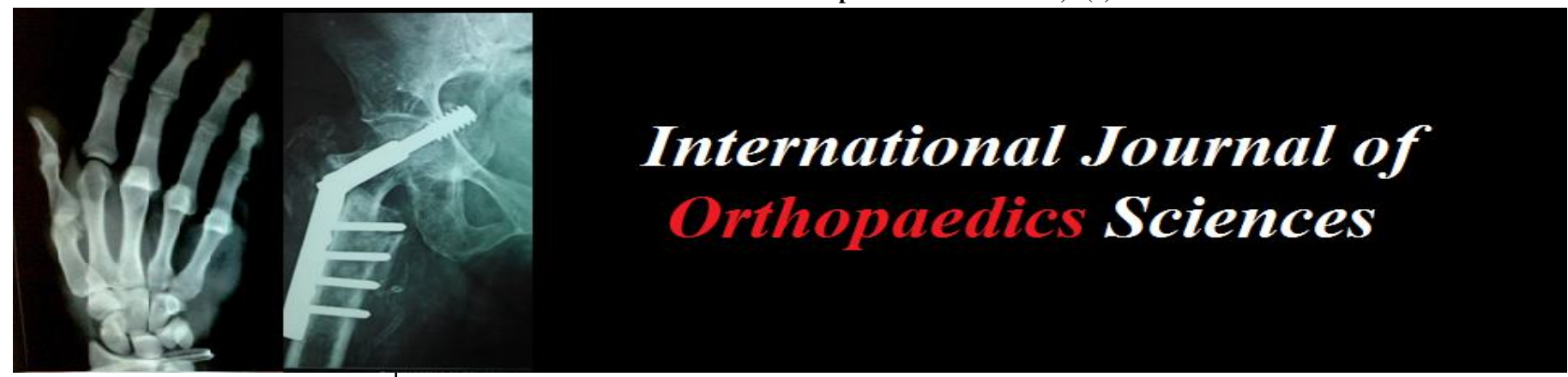

ISSN: $2395-1958$

IJOS 2018; 4(2): 790-792

(C) 2018 IJOS

www.orthopaper.com

Received: 22-02-2018

Accepted: 23-03-2018

Dr. Sachin Awasthi

Associate Professor,

Department of Orthopaedics,

Dr. RML Institute of Medical

Sciences, Lucknow,

Uttar Pradesh, India

Dr. Chandrasekhar Verma

Senior Resident,

Department of Orthopaedics,

Dr. RML Institute of Medical

Sciences, Lucknow,

Uttar Pradesh, India

Dr. Swagat Mahapatra

Assistant Professor,

Department of Orthopaedics,

Dr. RML Institute of Medical

Sciences, Lucknow,

Uttar Pradesh, India

Dr. Pankaj Aggarwal

Assistant Professor,

Department of Orthopaedics,

Dr. RML Institute of Medical

Sciences, Lucknow,

Uttar Pradesh, India

\section{Dr. SS Tripathy}

Associate Professor,

Department of Emergency

Medicine, Dr. RML Institute of

Medical Sciences, Lucknow,

Uttar Pradesh, India

Dr. Rajiv Ratan Singh Yadav Associate Professor,

Department of Emergency

Medicine, Dr. RML Institute of

Medical Sciences, Lucknow,

Uttar Pradesh, India
Correspondence

Dr. Chandrasekhar Verma

Senior Resident,

Department of Orthopaedics,

Dr. RML Institute of Medical

Sciences, Lucknow,

Uttar Pradesh, India

\section{Bilateral hip and knee replacement in ochronotic (Alkaptonuria) arthropathy: Tips, tricks \& precautions}

\author{
Dr. Sachin Awasthi, Dr. Chandrasekhar Verma, Dr. Swagat Mahapatra, \\ Dr. Pankaj Aggarwal, Dr. SS Tripathy and Dr. Rajiv Ratan Singh Yadav
}

DOI: https://doi.org/10.22271/ortho.2018.v4.i21.112

\section{Abstract}

Case: Alkaptonuria is a disorder of tyrosine metabolism having excretion of homogentisic acid in urine which gets dark when exposed to air. The disease is expressed as ochronosis of connective tissue with the significant involvement of large joints and spine. We present a case of a 56-year-old male having arthritis secondary to ochronosis of all large joints and bluish black discoloration of the bilateral sclera, skin of palm \& earlobes. During surgery, black discoloration of cartilage, menisci, joint capsule, and tendons was revealed in bilateral hip and knee replacement.

Conclusion: Due to stiffness of tissue encountered during surgical and anaesthetic procedure, this case serves as a learning high point for procedural modifications and surgical pearls which ensure a smooth management of the patient.

Keywords: Bilateral hip, knee replacement, ochronotic, Alkaptonuria, arthropathy, Tips, tricks \& precautions

\section{Introduction}

Alkaptonuria is a rare autosomal recessive disorder with incidence of 1 in 250000 million people worldwide but in higher frequency in Slovakia and dominical republic ${ }^{[1,2,3]}$. All the races and gender are affected in equal frequency. It more severely affects males [4]. Accumulation of homogentisic acid causes severe degeneration of spine and joints. Diagnosis is based on darkening of 24 hours collected urine sample when exposed to air. Urinary chromatography is not necessary for diagnosis. Symptomatic treatment in the form of antiinflammatory medication, tendon repair and joint replacement in severe arthritis is the standard management. High doses of vitamin $\mathrm{C}$ described in the older literature have no clinical advantage and no direct effect on urinary homogentisic acid levels. Nitinisone an inhibitor of 4-hydroxyphenyl pyruvate dioxygenase reduces production and thus urinary excretion of homogentisic acid ${ }^{[5]}$.

\section{Case presentation}

Our patient, a 56-year-old gentleman, was admitted to the department of Orthopaedics with complaints of pain and decreased range of motion in both hip and knee joints since the last 26 months. He had a history of voiding dark colored urine since the age of fifteen years and started developing pain in the large joints at the age of twenty-nine years. This pain was initially relieved with NSAIDs. With time stiffness in both hip and knee joints increased. At the age of thirty-five years, he presented with symptomatic gallstones which were treated with an open Cholecystectomy. At the age of forty-five, he developed bluish-black discoloration of his earlobes and also pigmentation in his sclera and palm. After urinary gas chromatography and other confirmatory investigations, he was diagnosed as a case of Alkaptonuria with Ochronotic arthropathy. By this age, he had developed significant difficulties in his activities of daily living due to hip and knee joint pain and stiffness. Radiologic examination of the spine revealed calcification of the intervertebral discs and narrowing of foramina. Due to stenosis in spine, ultrasound-guided spinal anesthesia was performed in lateral position in paramedian plane in both the total knee procedures and the right total hip arthroplasty procedure. In left total hip arthroplasty procedure after failure of USG guided subarachnoid block, awake 
fiberoptic intubation was done for general anesthesia. Biopsy taken at the time of surgery showed ochronosis in cartilage, joint capsule, menisci, and tendons. In total twenty-six months period, total arthroplasty of bilateral knee and hip joint was done with good results.

Outcome and follow-up Harris Hip Score

\begin{tabular}{|c|c|c|}
\hline & Right hip & Left hip \\
\hline Pre-operative & 8.15 & 22.3 \\
\hline Post-op 3 month & 47.2 & 64.6 \\
\hline Post-op 6 month & 53.3 & 71.6 \\
\hline Post-op 12 month & 63.9 & \\
\hline Post-op 17 month & 81.9 & \\
\hline
\end{tabular}

\section{Tegner Lysholm Knee Score}

\begin{tabular}{|c|c|c|}
\hline & Right knee & Left knee \\
\hline Pre-operative & 14 & 18 \\
\hline Post-op 6 month & 68 & 63 \\
\hline Post-op 12 month & 81 & 75 \\
\hline Post-op 24 month & 95 & 93 \\
\hline
\end{tabular}

In our case in twenty-six months follow up there was neither dislocation nor need of revision in any of the replaced joints. The low postoperative scores in left knee compared to right knee were improved drastically after left total hip arthroplasty. A similar situation was observed in the left hip. High Harris hip score in left hip at three-month postoperative period as compared to right hip could be attributed to replacement of all hip and knee joints by this time. Complaint of intermittent pain, stiffness on heavy work and mild morning stiffness of fewer than 15 minutes in all affected joints in postoperative period could be attributed to ongoing increasing stiffness in tissues due to ochronosis.

\section{Surgical tips}

- All the bone and soft tissue junctions are stiff \& Ochronotic. Overstretching of tissue will cause tear.

- Plan a longer incision as retractor are not very helpful due to stiffness.

- Small capillary bleeds should be taken care to avoid significant blood loss as collapse of wall of capillaries is doubtful.

- Always follow fascial planes and avoid injuring muscles.

- Make judicious use of cautery while working around capsule.

- Stretching of rotators is difficult around hip hence a judicious release is advised.

- Labrum and meniscus are black \& stiff. Gently debride them to get better closure.

- During total knee replacement procedure, proximal tibia \& distal femoral cuts can be increased if balancing and spacing is a problem.

- $\quad$ Soft tissue balancing during total knee replacement needs perfect assessment as tissues are not elastic.

- Subchondral bone is very hard. Use saw blades judiciously.

- Reaming of acetabular component should be meticulous as cartilage is Ochronotic.

\section{Anesthesia tips}

- $\mathrm{L}_{3} \mathrm{~L}_{4}$ space is the target space.

- X-ray of lumbar spine is advisable before attempting any prick.

- $\quad$ Stiff tissues create difficulty in the feeling of "giving way sensation." Epidural catheter needle is better because of thick and stout character

- Drug dosage should be judiciously calculated in view of decreased intrathecal space.

- Doses of Bupivacaine should be reduced in subarachnoid block and epidural anesthesia because of reduced spaces and chances of higher level of spinal anesthesia.

- All the arrangements for flexible guided intubation should be made before attempting regional anesthesia as chances of failure are high.

- Facilities for awake fiberoptic intubation should be kept ready in case of failure of regional anesthesia.

- Chest wall compliance is decreased; workstation settings should be checked to reduce chances of alveolar damage.

- We advise chest physiotherapy and intensive respirometry for two weeks preoperatively as chest compliance is reduced due to stiff joints and tissues.

- Urinary catheterization should be done day before surgery as it might need cystoscopic assistance.

- In lateral position make sure the abdomen is free.

\section{Discussion}

Alkaptonuria a rare autosomal recessive disorder caused by deficiency of Homogentesic acid oxidase in liver. Patients are free of symptoms in childhood and adolescence, but darkening of urine can be present ${ }^{[6,7,8]}$. Insufficiency of sucrose-isomaltase ${ }^{[9]}$ and neonatal hyperparathyroidism are co-inherited with alkaptonuria in some cases. In cases of nongenetic exogenous ochronosis, it can be caused by phenol, benzene, hydroquinone or trinifenoli. But in exogenous ochronosis, joint involvement in the form of arthropathy is not reported.

Arthropathy in alkaptonuria does not appear up to the third or fourth decade of life. This can be explained by the fact that there is good renal clearance of homogentisic acid up to that age ${ }^{[10]}$. Spontaneous tendon rupture and intervertebral disc herniation are often the first manifestations of disease ${ }^{[11,12]}$. Kumar et al. reported four spontaneous patellar tendon ruptures in 3 patients as the first symptom of disease ${ }^{[12]}$. However, in our case, large joint pain was the first symptom of Alkaptonuria. Calcification of intervertebral disc and narrowing of foramina are main features in spine. Arthritis of large peripheral joint is seen in almost all cases as patient grows up with age ${ }^{[13,14]}$. Rarely small joints of hands also get involved. Few Patients present with calcification of aortic valve and aortic stenosis and may require valve replacement surgery ${ }^{[15,16]}$. Aortic heart disease may also lead to ischaemic heart disease and myocardial infarction. Other systems involvement in the form of renal calculi, prostate calculi \& renal failure may present at a later age ${ }^{[17,18]}$.

Therapy is still nonspecific. Reduction of phenylalanine and tyrosine in diet and high intake of vitamin $\mathrm{C}$ are not with sound clinical evidence. Total joint replacement in advanced stage of arthritis improves quality of life significantly. Ozmanerva et al. reported that results of arthroplasty in Alkaptonuria are similar to arthroplasty performed for any osteoarthritic joint ${ }^{[19]}$. In our case results are good except mild stiffness on heavy work. Arthroplasty complications and loosening of components were not found by Spencer et al. following replacement of 11 joints of 3 patients in a twelve year follow up period ${ }^{[20]}$. Similar complications have not been observed in our case till date. As ochronosis is a metabolic disease, overall potential for failure is increased. ${ }^{[21,}$ 
${ }^{22]}$. Spencer et al. also reported a case in which patellar tendon was stiff which caused difficult dislocation of patella during surgery ${ }^{[20]}$. To avoid this, we took a longer incision and performed a generous release of the patellar tendon from tibial tuberosity to prevent avulsion.

\section{Conclusion}

In ochronosis in the absence of effective specific therapy, replacement arthroplasty improves the quality of life and joint mobility in affected patients drastically. As no particular contraindications and increased failure reported till yet, it is the best invasive therapy to improve the physical activity of the patients having severe arthritis of large joints.

\section{References}

1. Sahin G, Milcan A, Bagis S, Kokturk A, Pata C, Erdogan C. A case of ochronosis: upper extremity involvement. Rheumatol Int. 2001; 21:78-80.

2. Kumar RV, Rajasekaran S. Spontaneous tendon ruptures in alkaptonuria. J Bone Joint Surg [Br]. 2003; 85:883-6.

3. O'Brien WM, La Du BN, Bunim JJ. Biochemical, pathologic and clinical aspects of alcaptonuria, ochronosis and Ochronotic arthropathy: a review of world literature. Am J Med. 1963; 34(6):813-838, 15841962.

4. Harrold AJ, Alkaptonuric arthritis. J Bone Joint Surg Br. 1956; 38-B(2):532-538.

5. Fisher AA, Davis MW. Alkaptonuric ochronosis with aortic valve and joint replacements and femoral fracture: a case report and literature review. Clin Med Res. 2004; 2:209-15.

6. Bunim JJ, McGuire JS, Hilbish TF, Laster L, La du BN. Alcaptonuria, Clinical Staff Conference at the National Institutes of Health. Ann Intern Med. 1957; 47(6):12101224.

7. Minno AM, Rogers JA. Ochronosis: report of a case. Ann Intern Med. 1957; 46(1):179-183.

8. Al-Mefraji SH. Al-Mefraji Alkaptonuria in a 5-year-old boy in Iraq. East Mediterr Health J, 2008; 14(3):745-746.

9. Garnica AD, Cerda JJ, Maenard D, Preiser H, Crane K. Alcaptonuria and sucrase-isomaltase deficiency in three offspring of a consanguineous marriage. Acta Vitaminol Enzymol. 1981; 3(3):157-169.

10. Fisher AA, Davis MW. lkaptonuric ochronosis with aortic valve and joint replacements and femoral fracture: a case report and literature review. Clin Med Res. 2004; 2(4):209-215.

11. Reddy DR, Prasad VS. Alkaptonuria presenting lumbar disc prolapse: case report and review of literature. Spinal Cord. 1998; 36(7):523-524.

12. Manoj Kumar RV, Rajasekaran S. Spontaneous tendon ruptures in alkaptonuria. J Bone Joint Surg Br. 2003; 85(6):883-886.

13. O'Brien WM, Banfield WG, Sokoloff L. Studies on the pathogenesis of ochronotic arthropathy. Arthritis Rheum. $1961 ; 16(4): 137-152$.

14. Xu H, Wang J, Chen F, Hong Z, Zhang X, Ji X et al. (2015) Ochronotic arthritis of bilateral knees: a case report. Int J Clin Exp Med. 1961; 8(5):8185-8189.

15. Dereymaeker L, Van Parijs G, Bayart M, Daenen W, Lauwerijns J. Ochronosis and alkaptonuria: report of a new case with calcified aortic valve stenosis. Acta Cardiol. 1990; 45(1):87-92.

16. Vavuranakis M, Triantafillidi H, Stefanadis C, Toutouzas P. Aortic stenosis and coronary artery disease caused by alkaptonuria, a rare genetic metabolic syndrome. Cardiology. 1998; 90(4):302-304.

17. Venkataseshan VS, Chandra B, Graziano V, Steinlauf P, Marquet E. Alkaptonuria and renal failure: a case report and review of the literature. Mod Pathol. V; 5(4):464471.

18. Kazancioglu R, Taylan I, Aksak F, Durak H, Kumbasar B. Alkaptonuria and renal failure: a case report. J Nephrol. 2004; 17(3):441-445.

19. Ozmanevra R, Güran O, Karatosun V, Günal I. Total knee arthroplasty in ochronosis: a case report and critical review of the literature. Eklem Hastallk Cerrahisi. 2013; 24(3):169-172.

20. Spencer JM, Gibbons CL, Sharp RJ, Carr AJ, Athanasiou NA. Arthroplasty for ochronotic arthritis: no failure of 11 replacements in 3 patients followed up 6-12 years. Acta Orthop Scand. 2004; 75(3):335-338.

21. Kefeli M, Tomak Y, Can B, Bariş S. Arthroplasty for the treatment of joint degeneration caused by ochronosis in two cases. Acta Orthop Traumatol Turc. 2008; 42(2):139144.

22. Yilmaz A, Egilmez E. Knee Arthroplasty for ochronotic arthropathy. J Knee Surg. 2002; 15(4):231-232. 